\title{
Total knee Prosthesis on Stiff Knee over 55 Years
}

\author{
Pr. Ait El Hadj L ${ }^{1 *}$, Touati $\mathrm{A}^{2}$, Fourmas $\mathrm{S}^{2}$ and Pr. Yakoubi $\mathrm{M}^{3}$ \\ ${ }^{1}$ Orthopedic Surgery Department, Algeria \\ ${ }^{2}$ EHS Benaknoun, Algeria \\ ${ }^{3}$ Head of Department EHS Benaknoun, Algeria
}

ISSN: 2576-8875

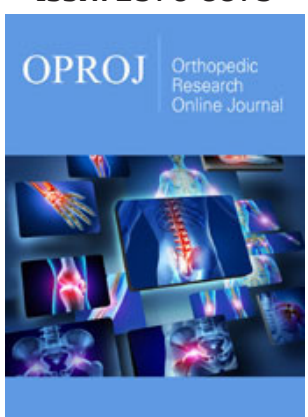

*Corresponding author: pr. Ait El Had L, Department of Orthopaedic Surgery, EHS Benaknoun, Algeria

Submission: 眥 December 13, 2019

Published: 眥December 19, 2019

Volume 6 - Issue 3

How to cite this article: Ait El Hadj L, Touati A, Fourmas S, Yakoubi M. Total knee Prosthesis on Stiff Knee over 55 Years. Ortho Res Online J. 6(3). OPROJ.000636.2019. DOI: 10.31031/OPROJ.2019.06.000636

Copyright@: Pr. Ait El Hadj L, This article is distributed under the terms of the Creative Commons Attribution 4.0 International License, which permits unrestricted use and redistribution provided that the original author and source are credited.

\begin{abstract}
The total knee prosthesis is now a reliable and reproducible intervention with a very satisfactory success rate. However, some situations expose to specific technical difficulties, this is the case especially; Total prostheses on stiff or stiff knee. We report an observation of a 69-year-old patient who suffered a traffic accident at an early age in whom an arthrodesis was performed. The patient had a total hinged prosthesis in his right knee in one time operative. Satisfactory result at 10 months postoperative, with a very satisfactory mobility. But 18 months after the patient consults for septic flow. He benefited from ablation of the prosthesis and setting up a spacer and adapted antibiotherapy. Before the persistence of the flow and the non-drying it ended up with a thigh amputation. This allowed us to focus on the technical difficulties, and the many possible complications. All series in the literature demonstrate high morbidity and the fact that the results are usually inferior to those reported for first total knee replacements, and that a mobility of approximately $70^{\circ}$ is generally obtained after eight to ten weeks. month postoperatively should be considered a very satisfactory result. But despite the $10 \%$ risk of amputation reported in the literature no series report this unfortunate result. Although these operations are cumbersome and the rehabilitation is long and difficult, the benefit for the patients is major, with many of them returning to an almost normal life.
\end{abstract}

Keywords: Total knee prosthesis; Stiff knee; Hinged prosthesis

\section{Introduction}

The total knee prosthesis is now a reliable and reproducible intervention with a very satisfactory success rate. The difficult nature of knee arthroplasty has a variable definition from one practitioner to another, and depends on his experience. Nevertheless, even for an experienced surgeon, some situations expose to specific technical difficulties, this is the case especially; Total prostheses on stiff or stiff knee. A solid fusion of the knee has several disadvantages. However, a successful fusion does not guarantee a satisfactory result as regards function; patients complain of awkwardness in sitting. The excessive hiking of the ipsilateral hip during walking requires more energy than normal, limits the patient's endurance, and causes low back pain. The ipsilateral hip may be hypothesized to be damaged by the direct impact that it sustains in the absence of the buffering action of a knee that has a satisfactory range of motion. The reported case is a rare indication to review the possibilities, limitations and consequences of this intervention.

\section{Observation}

Mr. B. Kader, 69 years old, comes to the service for an ankylosed and painful multioperated knee.

\section{History and history of the disease}

In his antecedents, we find a road accident at the age of 19 which caused a metaphysoepiphyseal fracture of the right femur, which was operated surgically and had an osteosynthesis, but with septic consequences. Two months later he had the equipment removed and an external fixator was put in place. 2 years later, due to the persistence of the infection and the pain, the patient had arthrodesis of his knee, with complete drying. the patient lived for 47 years with his arthrodesis without really complaining with just ipsilateral hip pain and a shortening of $8 \mathrm{~cm}$. At the age of 67 , he fractured the femoral neck in a screw which was 
complicated by non-union. what motivated the patient consulted at home or the indication of a total hip prosthesis is posed. Two years later, in front of the excellent result of the total hip prosthesis, the patient represents himself at the consultation wishing to recover the mobility of his knee. Before the infectious history of the patient, we did everything to dissuade him but despite the risks of this intervention wish to repeat and desire to have some mobility, disarthrodesis and the establishment of a prosthesis is decided.

\section{Clinical examination}

The patient is in good general condition, right knee extension in light valgus multioperated. Anterolateral approach in the ipsilateral hip. The clinical examination found a multicritical knee, with a flexum of $10^{\circ}$ (Figure 1) no mobility.
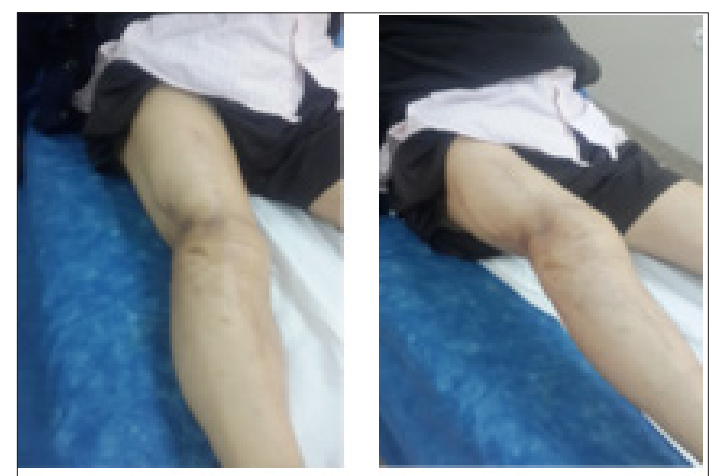

Figure 1: Clinical examination.

\section{Radiological assessment}

The radiological assessment consisted of standard radiographs of face, profile and patellofemoral incidence which objectivized on the frontal radiograph, a complete femora tibial arthrodesis, confirmed by the lateral radiograph, (Figure 2) with absence of the patella.
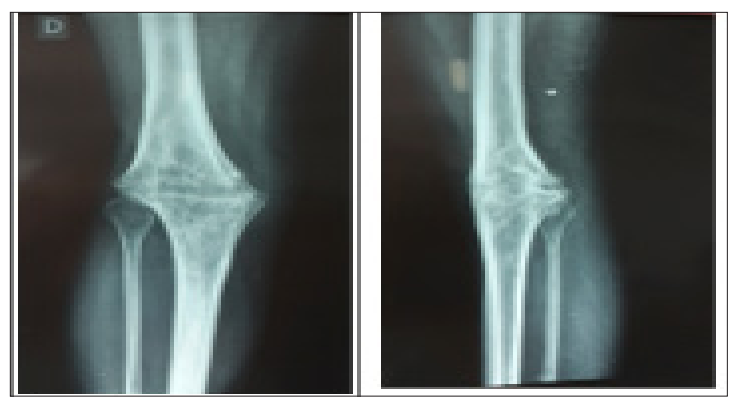

Figure 2: Radiological assessment.

\section{Results}

\section{Clinical conclusion}

In sum, it is a total postoperative ankylosis post traumatic on a knee multioperated in extension with $10^{\circ}$ of flexum. In front of this stiff knee and in front of repeated wish, kept informed of the risks of such a procedure. The intervention of disarthrodesis and placement of a total prosthesis is decided after 49 years of ankylosis. But before that, the patient is entrusted to a physiotherapist during the two to three months preceding the procedure to strengthen the quadriceps and hamstrings with simple static contractions. The procedure is performed under anesthesia spine, tourniquet at the root of the limb. Median incision. The exploration of the lateral ligaments found ligaments completely atrophied, it is therefore decided to put a Hinged joint total knee prosthesis with rotary pivot (Figure 3). No complication is noticeable, the restoration takes place within 48 hours under cover of a rigid knee that is maintained for 1 week. After 45 days the patient found a mobility of $0^{\circ} / 45^{\circ}$ after several re-education sessions. he was very satisfied with these numbers (Figure 4). Satisfactory result at 10 months postoperative, with a very satisfactory mobility. but 18 months after the patient consults for septic flow. He benefited from ablation of the prosthesis and setting up a spacer and adapted antibiotherapy. Before the persistence of the flow and the non-drying it ended up with a thigh amputation.
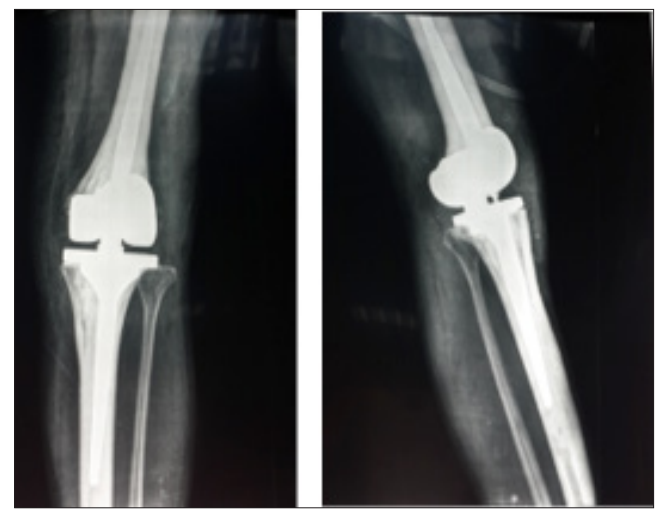

Figure 3: A Hinged joint total knee prosthesis.

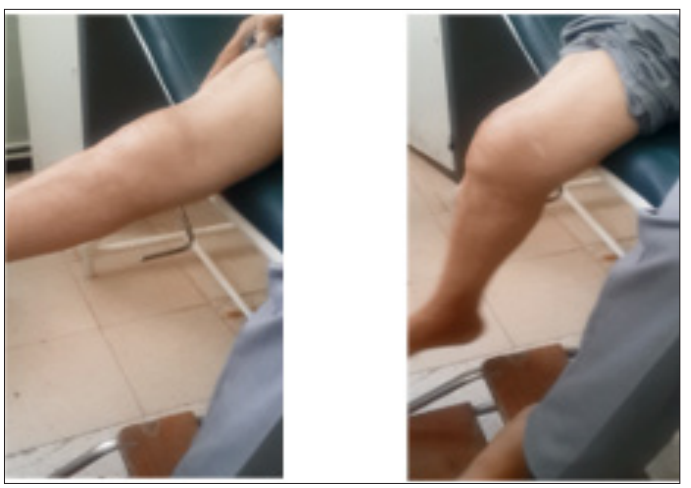

Figure 4: 45 days post-operative mobility.

\section{Discussion}

Stiffness is an indication of the choice of rotary pivot prostheses. In fact, to treat a tight knee stiffness, it is first of all to carry out a wide arthrolysis which, to be effective, must involve not only a disinsertion of the cruciate ligaments but also a disinsertion of the lateral ligaments. From the technical point of view, it is necessary to distinguish the stiffnesses which leave a mobility area of about thirty degrees to remain tighter ankyloses or arthrodesis [1,2]. Henkel et al. [3] reports on a series of 7 patients, 3 had open arthrolysis for adhesion and arthrofibrosis, 2 patients had a gastro- 
meningeal flap for skin necrosis and 1 patient had neurolysis of the peroneal nerve for painful paresis. Takedown of a formal knee fusion with TKA should be carried out only in carefully selected cases and in highly motivated patients with realistic expectations [4]. In the event of failure of the resumption, it may be necessary to resort to an arthrodesis of realization always difficult, or to an arthroplastic resection, even to amputation of thigh [ 5-7]. The severity of a septic awakening must delay any prosthetic surgery on such grounds until a five-year delay has elapsed since the last infectious manifestations. In a study of primary TKA, Jansen et al. [8] found higher infection rates with constrained or hinged prostheses [8]. All series in the literature demonstrate high morbidity and the fact that the results are usually inferior to those reported for first total knee replacements, and that a mobility of approximately $70^{\circ}$ is generally obtained after eight to ten weeks. month postoperatively should be considered a very satisfactory result [9]. But despite the $10 \%$ risk of amputation reported in the literature no series report this unfortunate result

\section{Conclusion}

Although these operations are cumbersome and the rehabilitation is long and difficult, the benefit for the patients is major, with many of them returning to an almost normal life. Publications of knee replacement arthroplasties in extension are rare. They report few cases with a complication rate close to $50 \%$. No author recommends this intervention.

\section{References}

1. Reignier B (1993) AXEL hinged knee prosthesis. Traumatological Orthopedics.

2. Reignier B (2002) Total knee prostheses hinged rotary: Results. Elsevier Scientific Publications, Netherlands.

3. Boldt JG, Henkel TR, Drobny TK, Munzinger UK (2001) Total knee arthroplasty after formal knee fusion using unconstrained and semiconstrained components: A report of 7 cases. J Arthroplasty 16(6): 768-776.

4. Kim YH, Cho SH, Kim JS (1999) Total knee arthroplasty in bony ankylosis in gross flexion. J Bone Joint Surg Br 81(2): 296-300.

5. Jämsen E, Huhtala H, Puolakka T, Moilanen T (2009) Risk factors for infection after knee arthroplasty. A register-based analysis of 43,149 cases. J Bone Joint Surg Am 91(1): 38-47.

6. Cameron HU, Hu C (1996) Results of total knee arthroplasty following takedown of formal knee fusion. J Arthroplasty 11(6): 732-737.

7. Naranja RJ, Lotke PA, Pagnano MW, Hanssen AD (1996) Total knee arthroplasty in a previously ankylosed or arthrodesed knee. Clin Orthop Relat Res 331: 234-237.

8. Cholewinskia P, Putmana S, Vasseura L, Migauda H, Duhamela A, et al. (2015) Long-term outcomes of primary constrained condylar knee arthroplasty. Orthop Traumatol Surg Res 101(4): 449-454.

9. Massin P, Bonnin M, Paratte S, Vargas R, Piriou P, et al. (2011) Total knee replacement in post-traumatic arthritic knees with limitation of flexion. Orthop Traumatol Surg Res 97(1): 28-33. 